\title{
Changes in Carbohydrate Composition of the Different Bulb Components of Nerine bowdenii W. Watson (Amaryllidaceae)
}

\author{
K.I. Theron and G. Jacobs \\ Department of Horticultural Science, University of Stellenbosch, Private Bag X1, 7602 Matieland \\ (Stellenbosch), Republic of South Africa
}

Additional index words. cut flower, reducing sugars, reserves, starch

\begin{abstract}
Flowering-size Nerine bowdenii bulbs were sampled from a commercial planting at 2-week intervals from 13 Aug. 1991 to 14 June 1992. They were dissected, the dry weight of foliage and leaf bases was recorded, and carbohydrate analysis was performed on the foliage leaves, leaf bases, and roots. Starch was the dominant storage carbohydrate, and leaf bases were the principal bulb structures where it was stored. Changes in starch content closely followed dry weight changes in the bulb. When exposed to low temperatures, starch was converted to sugars. Except for these high levels in the leaf bases, sugars, expressed both as concentration and total content, were low in bulb components, indicating continued export and conversion to starch. Low sugar levels during the period that florets in the current season's inflorescence develop to stage Late $G$ (gynoecium elongated, carpels fused) is implicated in the abortion of the inflorescence.
\end{abstract}

Carbohydrate reserves stored in fleshy leaf bases, fleshy scales, or corms are important for the initial growth of deciduous geophytic plants (Miller, 1992). Conversion of starch to sugars in response to low temperatures has been reported in tulip (Aung et al., 1976; Davies and Kempton, 1975; Haaland and Wickstrøm, 1975), in Lilium longiflorum (Miller and Langhans, 1990), and in potato (Isherwood, 1973). The conversion in tulip occurs in response to an increased activity of $\alpha$-amylase and $\alpha$-glucanphosphorylase (Haaland and Wickstrøm, 1975). Increased sugar levels are probably necessary to protect the bulb against low temperature damage (Weiser, 1970).

As in other plants, (Miller, 1992) starch is the major storage carbohydrate in tulip (De Hertogh et al., 1983) and in L. longiflorum, although glucomannans are also present in the latter (Miller and Langhans, 1990). Fructans (fructosylsucrose) are also commonly found in storage organs of Liliaceae, Amaryllidaceae, and Iridaceae (Miller, 1992).

The time of carbohydrate accumulation in relation to flowering varies in geophytes. In gladiolus, the increase in dry weight of the daughter corm occurs after flowering (Halevy, 1985). In tulip, daughter bulbs increase in starch after flowering (De Hertogh et al., 1983). But in Nerine bowdenii, dry weight of the leaf bases increases before anthesis (Theron and Jacobs, 1994b).

In $N$. bowdenii, a geophyte with a synanthous growth habit (foliage emerges before anthesis), inflorescence development is nourished by current photosynthates produced by the foliage (Theron and Jacobs, 1994b). In geophytes with a hysteranthous growth habit (foliage emerges after anthesis) e.g., Nerine sarniensis, reserves are allocated to inflorescence development.

Inflorescence quality and flowering percentage in $N$. bowdenii is related to bulb size and carbohydrate content (Theron and Jacobs, 1992). Previously, it was found that starch and sugars (reducing sugars and sucrose) occur at high levels in leaf bases of $N$. bowdenii at the time bulbs are lifted in winter (Theron and Jacobs, unpublished data). The objectives of this study were to determine which bulb components act as storage organs for carbohydrates, and to determine

Received for publication 6 Mar. 1995. Accepted for publication 11 Sept. 1995. We thank A. Doorduin and S. Oudhuis, Oak Valley Flowers, for facilities, plant material, and supervision, S.A. le Grange for editorial assistance, and M. Lambrechts and C.W. Maart for technical assistance. The cost of publishing this paper was defrayed in part by the payment of page charges. Under postal regulations, this paper therefore must be hereby marked advertisement solely to indicate this fact. the changes in carbohydrate content and concentration of the different bulb components during the growing season.

\section{Materials and Methods}

Plant material. Bulbs from a commercial planting of $N$. bowdenii were used. They were grown in a $64 \%$ shade house in the Elgin region of the Western Cape (lat. $34^{\circ} 54^{\prime} \mathrm{S}$ ). The light intensity in the shade house, recorded on a sunny day in midsummer at $1100 \mathrm{HR}$, was 440 $\mu \mathrm{mol} \cdot \mathrm{m}^{-2} \cdot \mathrm{s}^{-1}$. The Elgin climate is Mediterranean with cool, wet winters and dry, hot summers. The average annual rainfall is about $1000 \mathrm{~mm}$ (Dept. of Agriculture and Water Supplies, 1989). Bulbs (12-14 cm circumference) were planted in spring (1 Oct. 1990) at a density of 160 bulbs $/ \mathrm{m}^{2}$ and remained in situ during the winter of 1991. Bulbs were irrigated, fertilized, and treated for pests according to standard commercial practices.

Terminology. Nerine bulbs are composed of a series of growth units (Van Brenk and Benschop, 1993). A growth unit undergoes a vegetative phase where leaves are formed, followed by a reproductive phase where the apex is transformed into an inflorescence. At anthesis, in the fall (March), at least three growth units are evident in a flowering size bulb (Theron and Jacobs, 1994a). The oldest growth unit consists of the current season's inflorescence $(\mathrm{N})$, which is subtended by leaf bases. In some bulbs, leaf bases from the preceding growth unit $(\mathrm{N}-1)$ also are present. Two to three daughter bulbs are present in the axils of the oldest leaf bases. The second growth unit is composed of a developing inflorescence $(\mathrm{N}+1)$, which reaches anthesis in the next fall. It is subtended by fully expanded leaves that senesced during winter. Developing inflorescence $\mathrm{N}+2$ is subtended by young, unexpanded leaves, and it constitutes the third growth unit. The leaves of growth unit $\mathrm{N}+2$ will expand after winter; whereas the inflorescence $\mathrm{N}+2$ reaches anthesis in the second fall. Two to three leaf primordia develop in the fourth growth unit $(\mathrm{N}+3)$, and the apex is vegetative (Theron and Jacobs, 1994a).

Data recorded. At 2-week intervals, from 13 Aug. 1991 (late winter, just before foliage emergence) to 14 June 1992 (after foliage senescence), 10 bulbs were sampled at random and brought to our laboratory. Bulbs were dissected and dry weight and carbohydrate content of leaf bases $(\mathrm{N}-1, \mathrm{~N}$, and $\mathrm{N}+1)$, foliage $(\mathrm{N}+1)$ and roots were determined. As it was difficult to determine the total dry weight of the roots, only the carbohydrate concentration was determined. On 
each sampling date, five repetitions of two bulbs each were analyzed.

Carbohydrate extraction and analysis: All samples were lyophilized, milled to a fine powder, and stored in sealed containers at $-20 \mathrm{C}$.

Extraction. Half a gram of sample, to which $0.5 \mathrm{~g}$ PVP (Polyvinylpyrrolidone, insoluble) was added, was extracted with 25 $\mathrm{ml} 80 \%$ ethanol by shaking for $14 \mathrm{~h}$ in a $100 \mathrm{ml}$ Erlenmeyer flask. The contents were transferred quantitatively to $50-\mathrm{ml}$ centrifuge tubes and centrifuged at $\approx 3500 \mathrm{rpm}$ for $10 \mathrm{~min}$. The supernatant was decanted into $250 \mathrm{ml}$ beakers and the pellet homogenized with distilled water and centrifuged. The supernatants were combined and the alcohol evaporated on a steambath. This aqueous fraction contained the alcohol/water-soluble sugars and the pellet contained the starch fraction.

Reducing sugars. The aqueous fraction was transferred to $100 \mathrm{ml}$ volumetric flasks and $10 \mathrm{ml}$ glycerol-C (1000-ml 50\% water/glycerol $+200 \mathrm{~g}$ activated charcoal) added. Samples were made up to volume with distilled water and filtered using no. 3 filter paper. Sucrose was hydrolysed with invertase and then all reducing sugars were determined after a copper reduction reaction on a computerized Technicon Auto Analyser II according to their method (1984).

Starch. The starch fraction was transferred to $100 \mathrm{ml}$ volumetric flasks with acetate buffer, $\mathrm{pH} 4.8$ (0.2 M acetic acid + 0.2 M sodium acetate), placed in a boiling water bath for $2 \mathrm{~h}$, cooled to below 60C, and then $100 \mu \mathrm{l}$ AGS (Amyloglucocidase, $200 \mathrm{mg}$ in $10 \mathrm{ml}$ acetate buffer) was added. After incubation for $18 \mathrm{~h}$ at $55 \mathrm{C}$, flasks were made up to volume with distilled water and then filtered through no. 3 filter paper. Starch was determined colorimetrically as glucose by a computerized Technicon Auto Analyser II according to their method (1985).

Data analysis. Data were analyzed using the CORR (Correlation) and GLM (General Linear Models) Procedures in the SAS program (SAS Inst., Cary, N.C.)

\section{Results and Discussion}

Fructan determinations were done on a selected number of samples from all bulb components at different times during the season, but the levels were low (data not presented).

Starch is the dominant storage carbohydrate in N. bowdenii, and leaf bases are the principal bulb structures where it is stored (Fig. 1). Neither leaves nor roots are important storage organs for starch as indicated by low starch concentrations in these organs (Fig. 2). The total starch content of all leaf bases was highly correlated with the total dry weight of leaf bases (Table 1). Changes in the starch content therefore closely followed the dry weight changes in the bulb. The total starch content decreased during the leafless phase of the bulb, and until the new, developing leaves produced photosynthates in excess of those used for respiration and allocation to roots and daughter bulbs (Fig. 1). The decrease in starch content of leaf bases $\mathrm{N}-1$ and $\mathrm{N}$ was more than what was used for respiration and allocation, as the sugar content increased during this time (Fig. 3). This was due to the conversion of starch to sugars in response to low temperatures in August, the coldest month in the region (Dept. of Agriculture and Water Supplies, 1989). This phenomenon is observed in other bulbous plants (Aung et al., 1976; Davies and Kempton, 1975; Haaland and Wickstrøm, 1975), and is probably important in the acclimatization of the bulb to low temperature stress (Weiser, 1970). An increase in the total starch content occurred once the longest leaf had reached $\approx 50 \%$ of its final length and continued until 25 Feb. 1992 when rapid growth of inflorescence $N$ started. This increase in total starch content was negatively correlated with starch content in the $\mathrm{N}-1$ leaf bases, indicating that the old leaf bases disintegrated progressively as the season advanced (Fig. 1). Starch accumulation in the $\mathrm{N}$ leaf bases began $\approx 6$ weeks before starch accumulation in leaf bases $\mathrm{N}+1$; however, the latter reached maximum starch levels earlier than the $\mathrm{N}$ leaf bases (Fig. 1). In both structures the total starch content was correlated with their dry weight, 0.7658 and 0.9699 for the $\mathrm{N}$ and $\mathrm{N}+1$ leaf bases respectively (Table 1).

During the period of inflorescence growth, the total starch content in bulbs decreased and this continued until after leaf senescence when the study was terminated. This decrease was accompanied by a decrease in the starch content of leaf bases $\mathrm{N}-1$ and $\mathrm{N}$, but not in leaf bases $\mathrm{N}+1$. This indicates that when leaf-produced photosynthates become limiting for inflorescence growth and daughter bulb growth, starch in leaf bases $\mathrm{N}$ is used. It is important to maintain functional leaves for as long as possible after anthesis to ensure high starch content in bulbs.

Correlation coefficients of 0.8 or higher were found between the total starch content and the starch concentration of the different
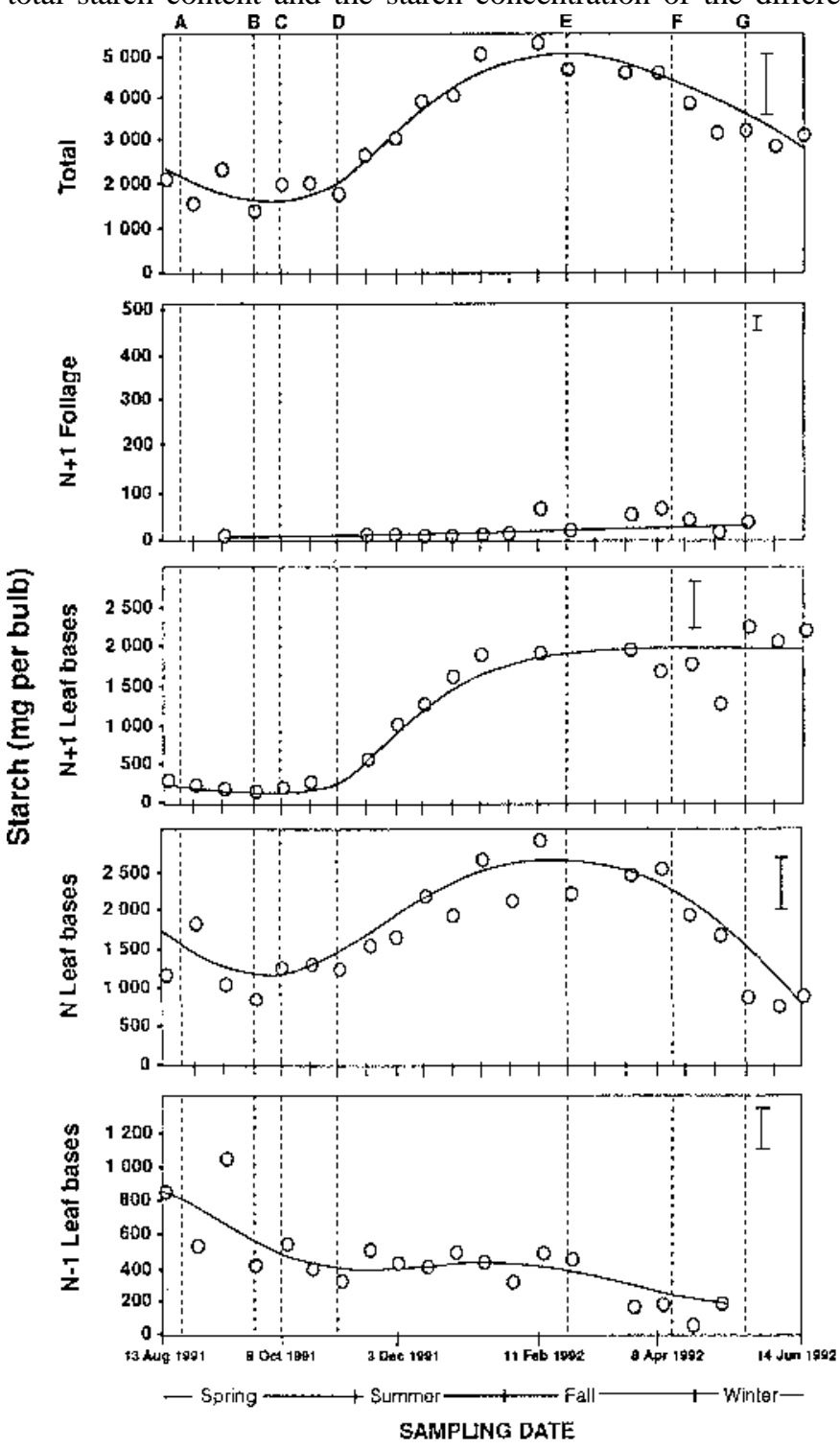

Fig. 1. Changes in starch content (mg per bulb) of the different growth units of Nerine bowdenii during the growing season. (A) Leaf emergence; (B) longest foliage leaf $50 \%$ of final length (C) longest foliage leaf $60 \%$ of final length; (D) extension growth of longest foliage leaf concluded; (E) start of rapid scape elongation; (F) anthesis of first inflorescence; (G) foliage senescent. Bar represents 5\% LSD value. Total $=\mathrm{N}-1, \mathrm{~N}$ and $\mathrm{N}+1$ leaf bases and $\mathrm{N}+1$ foliage. 


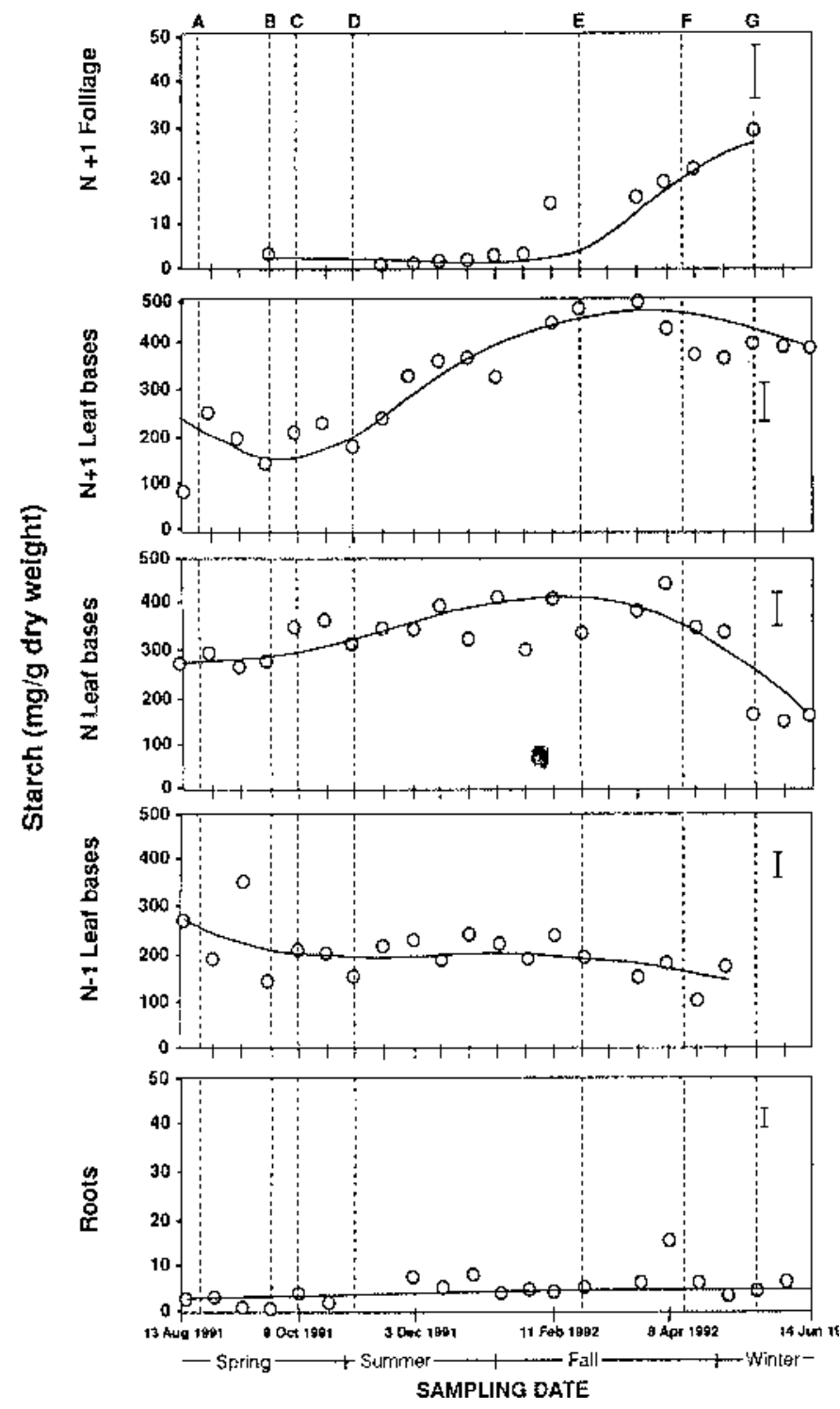

Fig. 2. Changes in starch concentration ( $\mathrm{mg} / \mathrm{g}$ dry weight) of the different growth units of Nerine bowdenii during the growing season.(A)Leaf emergence;(B) longest foliage leaf $50 \%$ of final length; (C) longest foliage leaf $60 \%$ of final length; (D) extension growth of longest foliage leaf concluded;(E) start of rapid scape elongation; $(\mathbf{F})$ anthesis of first inflorescence; $(\mathbf{G})$ foliage senescent. Bar represents 5\% LSD value. generations of leaf bases (Table 1). Starch concentration essentially followed the trend of total starch in leaf bases. The only exception was that the starch concentrations were relatively higher than the total starch content early in the season as compared to later in the growing season (Fig. 2). The total starch content in leaf bases $\mathrm{N}$ and $\mathrm{N}+1$ was therefore dependent on the dry weight and on the concentration of starch. Mostly, bulb quality is related only to size, while the starch concentration is also implicated.

Reducing sugars and sucrose constitute the main transportable carbohydrates in N. bowdenii bulbs (Theron and Jacobs, unpublished data). Except for the high sugar level in leaf bases $\mathrm{N}$ and $\mathrm{N}-$ 1 in response to low temperatures, sugars, expressed both as total or as concentration, were low in bulb structures (Figs. 3 and 4). In the N-1 leaf bases this indicated continuous export of sugars with a concurrent decrease in starch of the $\mathrm{N}-1$ leaf bases as the growing season progressed. In $\mathrm{N}$ leaf bases, low sugar levels were associated with an increase in starch, indicating a rapid conversion of imported sugar to starch. The sugar content of the $\mathrm{N}+1$ leaf bases increased until after the longest foliage leaf was fully grown. It then decreased and remained at low levels until the study was terminated (Figs. 3 and 4). This increase possibly reflected on the $\mathrm{N}+1$ leaf bases as transporting structures for leaf produced sugars to other bulb components, e.g., leaf bases N. Once the leaf bases N+1 started to accumulate starch, the sugar level dropped again, reflecting a rapid conversion of sugar to starch in leaf bases $\mathrm{N}+1$. Both the sugar content and concentration of foliage $\mathrm{N}+1$ increased during the period of foliage elongation. However, once the export of sugars started, the concentration dropped and remained at low levels until leaf senescence (Fig. 4).

During the period when individual florets in inflorescence $\mathrm{N}$ advanced to stage Late $\mathrm{G}$ (gynoecium elongated, carpels fused) in January (Theron and Jacobs, 1994a), sugar levels in the bulb were relatively low. This was due to the rapid conversion of leaf produced sugars into starch, first in leaf bases $\mathrm{N}$, and thereafter in leaf bases $\mathrm{N}+1$. Abortion of inflorescence $\mathrm{N}$ occurs during this period (Theron and Jacobs, 1992), implying that low sugar levels could be involved in inflorescence abortion. Sink strength (sink mobilizing ability) is a function of sink size and sink activity (Daie, 1985). Inflorescence $\mathrm{N}$ is probably a weak sink, firstly, because it is small and secondly, due to its low sink activity. Its sink activity increases as more florets reach stage Late G; thereafter, sink size increases as rapid growth starts (Theron and Jacobs, 1994a). Both of these increase sink strength of inflorescence $\mathrm{N}$.

Table 1. Correlation between starch and sugar content, and dry weight or starch and sugar concentration in bulbs of Nerine bowdenii.

\begin{tabular}{|c|c|c|c|c|c|}
\hline & All leaf bases & $\mathrm{N}-1$ leaf bases & $\mathrm{N}$ leaf bases & $\mathrm{N}+1$ leaf bases & $\mathrm{N}+1$ foliage \\
\hline \multicolumn{6}{|c|}{ Total starch } \\
\hline Dry wt (g) & $0.7728^{z}$ & 0.8668 & 0.7658 & 0.9699 & -0.4062 \\
\hline Significance & $0.0001^{\mathrm{y}}$ & 0.0001 & 0.0001 & 0.0001 & 0.1185 \\
\hline $\begin{array}{l}\text { Starch concn. } \\
\mathrm{mg} \cdot \mathrm{g}^{-1}\end{array}$ & --- & 0.9144 & 0.7963 & 0.8508 & 0.8032 \\
\hline Significance & --- & 0.0001 & 0.0001 & 0.0001 & 0.0002 \\
\hline \multicolumn{6}{|c|}{ Total sugars } \\
\hline Dry wt (g) & --- & 0.8051 & -0.4729 & 0.0671 & 0.8646 \\
\hline Significance & --- & 0.0001 & 0.0262 & 0.7667 & 0.0001 \\
\hline $\begin{array}{l}\text { Sugar concn. } \\
\mathrm{mg} \cdot \mathrm{g}^{-1}\end{array}$ & --- & 0.9360 & 0.9543 & 0.5363 & 0.6247 \\
\hline Significance & --- & 0.0001 & 0.0001 & 0.0101 & 0.0073 \\
\hline
\end{tabular}

${ }^{\mathrm{z}}$ Pearson correlation coefficients.

yProbability $>$ R under Ho: Rho $=0$. 


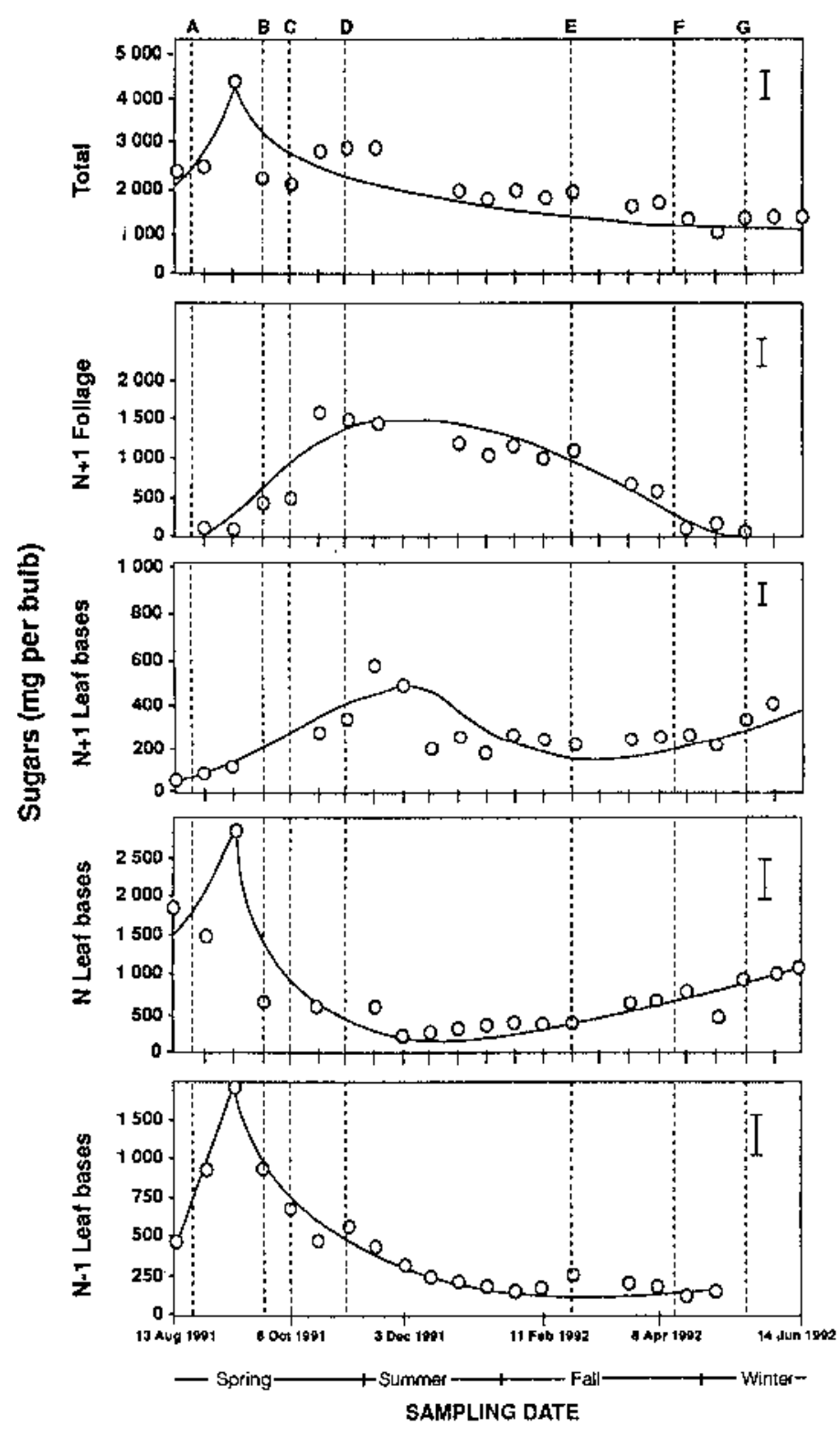

Fig. 3. Changes in sugar(reducing sugars and sucrose) content (mg per bulb) of the different growth units of Nerine bowdenii during the growing season. (A) Leaf emergence; (B) longest foliage leaf $50 \%$ of final length; (C) longest foliage leaf $60 \%$ of final length; (D) extension growth of longest foliage leaf concluded; (E) start of rapid scape elongation; (F) anthesis of first inflorescence; $(\mathbf{G})$ foliage senescent. Bar represents $5 \%$ LSD value. Total $=\mathrm{N}-1, \mathrm{~N}$, and $\mathrm{N}+1$ leaf bases and $\mathrm{N}+1$ foliage.

\section{Literature Cited}

Aung, L.H., R.D. Wright, and A.A. De Hertogh. 1976. Carbohydrate and dry matter changes in organs of Tulipa gesneriana L. during low temperature treatment. HortScience 11:37-39.

Daie, J. 1985. Carbohydrate partioning and metabolism in crops. Hort. Rev. 7:69-107.

Davies, J.N. and R.J. Kempton. 1975. Carbohydrate changes in tulip bulbs during storage and forcing. Acta Hort. 47:353-363.

De Hertogh, A.A., L.H. Aung, and M. Benschop. 1983. The tulip: Botany, usage, growth, and development. Hort. Rev. 5:45-125.

Department of Agriculture and Water Supplies. 1989. Climatic statistics of the winter rainfall region. Sect. Agromet., Elsenburg, S. Africa.

Haaland, E. and A. Wickstrøm. 1975. The effect of storage temperature on carbohydrate interconversion in tulip bulbs. Acta Hort. 47:371-376.

Halevy, A.H. 1985. Gladiolus, p. 63-70. In: A.H. Halevy (ed.). CRC handbook of flowering vol. III. CRC Press, Boca Raton, Fla.

Isherwood, F.A. 1973. Starch-sugar interconversion in Solanum
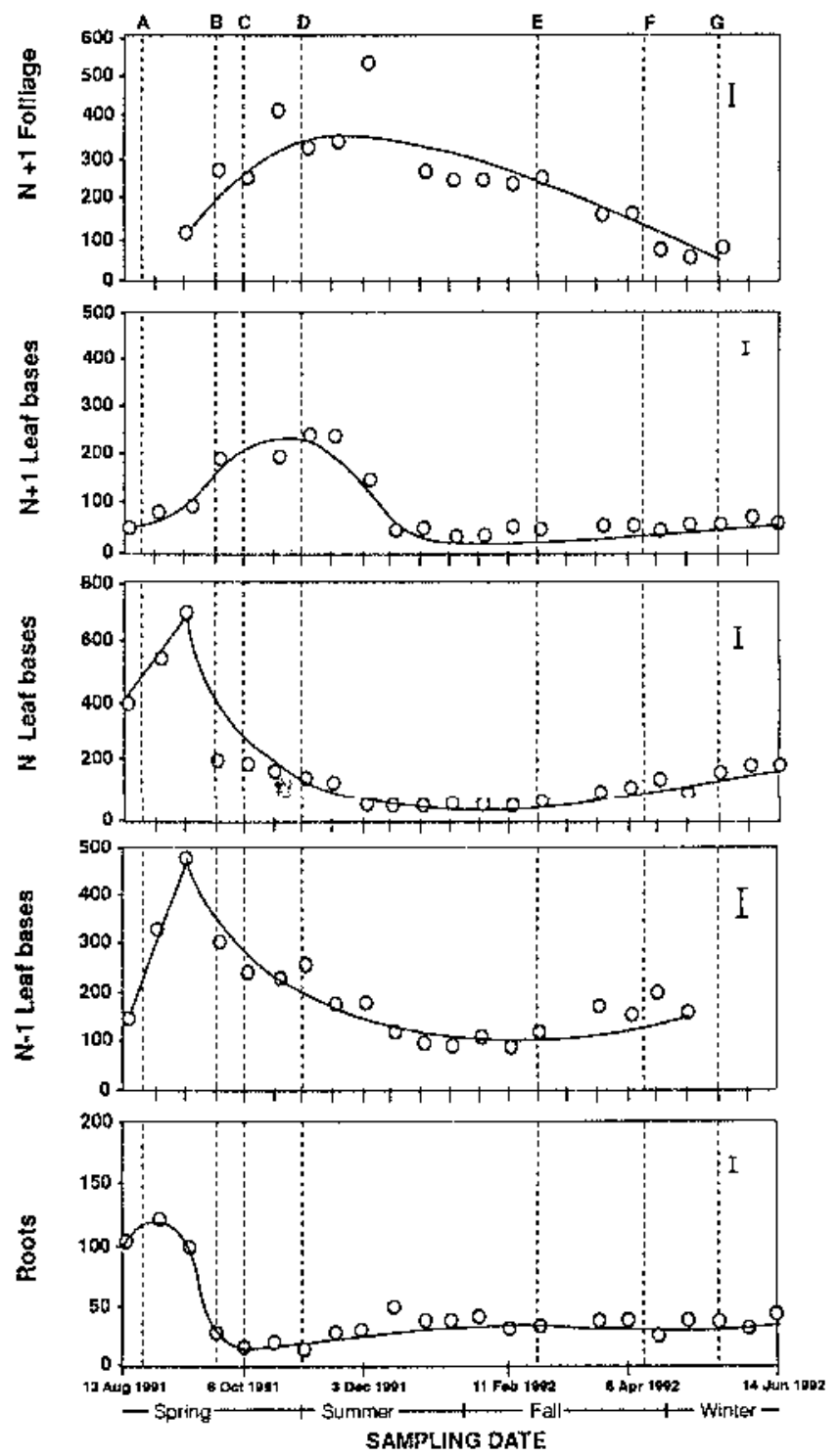

Fig. 4. Changes in sugar (reducing sugar and sucrose) concentration (mg/g dry weight) of the different growth units of Nerine bowdenii during the growing season (A) Leaf emergence; (B) longest foliage leaf 50\% of final length; (C) longest foliage leaf $60 \%$ of final length; (D) extension growth of longest foliage leaf concluded; (E) start of rapid scape elongation; $(\mathbf{F})$ anthesis of first inflorescence; $(\mathbf{G})$ foliage senescent. Bar represents 5\% LSD value.

tuberosum. Phytochemistry 12:2579-2591.

Miller, W.B. 1992. A review of carbohydrate metabolism in geophytes. Acta Hort. 325:239-249.

Miller, W.B. and R.W. Langhans. 1990. Low temperature alters carbohydrate metabolism in Easter lily bulbs. HortScience 25:463-465.

Technicon Auto Analyser. 1984. Technicon Auto Analyser II. Industrial method no. 736-831.

Technicon Corporation. 1985. Glu-cinet method.

Theron, K.I. and G. Jacobs. 1992. Inflorescence abortion in Nerine bowdenii W. Watts [sic]. Acta Hort. 325:97-103.

Theron, K.I. and G. Jacobs. 1994a. Periodicity of inflorescence initiation and development in Nerine bowdenii W. Watson (Amaryllidaceae). J. Amer. Soc. Hort. Sci. 119:1121-1126.

Theron, K.I. and G. Jacobs. 1994b. Comparative growth and development of Nerine bowdenii W. Watson: Bulbs in situ vs. replanted. HortScience 29:1493-1496.

VanBrenk, G. and M. Benschop. 1993.Nerine,p.559-588.In: A.deHertogh and M. le Nard (ed.). The physiology of flower bulbs. Elsevier, Amsterdam.

Weiser, C.J. 1970. Cold resistance and acclimation in woody plants. HortScience 5:403-410. 